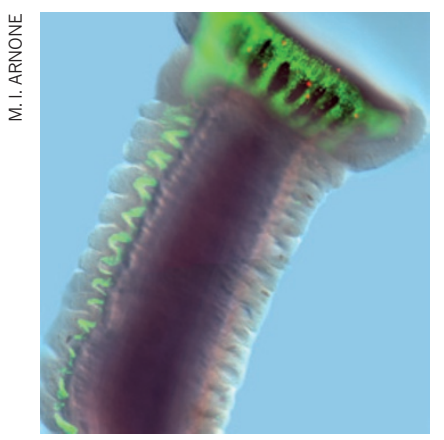

her colleagues show that the feet of Strongylocentrotus purpuratus (pictured) contain a type of photoreceptor cell found in many other animals, including vertebrates. The researchers found that two key photoreceptor genes (pictured in dark purple and red) are expressed in the feet.

The photoreceptor cells connect to the animals' nervous system (green). The authors suggest that the entire sea urchin can function as a large compound eye, and that the shadow cast by the animal's opaque skeleton on some of the light-sensing cells may enable directional vision.

Proc. Natl Acad. Sci. USA doi:10.1073/pnas.1018495108 (2011)

\section{Light switch at the speed of light}

Optical devices promise to be faster than their electronic counterparts, but to achieve this, swifter switches are needed to route the flow of information encoded by light. Georgios Ctistis and Willem Vos at the University of Twente in the Netherlands and their colleagues have built a switch that changes from off to on to off in just one-trillionth of a second. They used a laser beam to change the refractive index of a microcavity made from gallium arsenide and aluminium arsenide layers, thereby switching the wavelength of light the cavity transmits most readily.

The device is limited by the speed of light in the cavity rather than by the response time of the switch's materials.
On the basis of the results, photonic chips could switch 100 times faster than state-of-theart electronic chips.

Appl. Phys. Lett. 98, 161114

(2011) CELL BIOLOGY

\section{Deeper insight into a single cell}

By using a variety of transition metals to tag cellular proteins, researchers have simultaneously measured up to 34 characteristics in individual cells. That's more than double the number tracked with previous methods.

Flow cytometry has

long been an important tool for discovering and characterizing subtypes of cell. It uses fluorescent markers to concurrently follow the activities of up to 15 cellular parameters. In 'mass cytometry', however, Garry Nolan of Stanford University in California and his colleagues used mass spectrometry to measure changes in the levels of metal-tagged proteins. Mass spectrometry has high resolution, allowing many signals to be measured at once.

The authors monitored fluctuations in 34 parameters in healthy human bonemarrow cells, and uncovered several new cell-signalling events. They also followed the cells' responses to the cancer drug dasatinib.

Science 332, 687-696 (2011)

\section{MOLECULAR BIOLOGY}

\section{Protein maker and gene regulator}

Long thought to simply assemble cellular proteins from RNA molecules, ribosomes may also control the expression of key development genes.

Maria Barna at the University of California, San Francisco, and her team discovered that mouse strains with short, kinked tails (pictured) and an extra rib are deficient in a protein called RPL38 - one of the dozens

COMMUNITY CHOICE

The most viewed papers in science

\title{
NANOTECHNOLOGY
}

\section{Solar cells improve with acid}

\section{HIGHLY READ \\ on pubs.acs.org in April}

A sprinkling of nitric acid doubles the efficiency of hybrid silicon-nanotube photovoltaic cells.

Typical hybrids, made of networks of carbon nanotubes laid on crystalline silicon, might be cheaper to make than conventional all-silicon cells. Yet, at best, they convert a meagre $6-7 \%$ of sunlight's power into electricity, well under half the performance of commercial silicon cells. Anyuan Cao at Peking University, Beijing, Dehai Wu at Tsinghua University, also in Beijing, and their colleagues show that adding dilute nitric acid boosts the hybrids' efficiencies to $11-13 \%$. The acid improves contact between the silicon and the nanotubes, providing more paths for charge carriers to exit the cell and produce external current.

Nano Lett. doi:10.1021/nl2002632 (2011) that make up the ribosome. The defect seems to limit the production of some Hox proteins, which help to form the body plan. In normal mouse embryos, RPL38 is expressed at its highest levels in tissues in which the short-tailed mutants show defects, such as the vertebrae. Moreover, the expression of many of the ribosome's 79 constituent proteins varied widely from tissue to tissue in these embryos, suggesting that ribosomes may have specialized functions. Cell 145, 383-397 (2011)

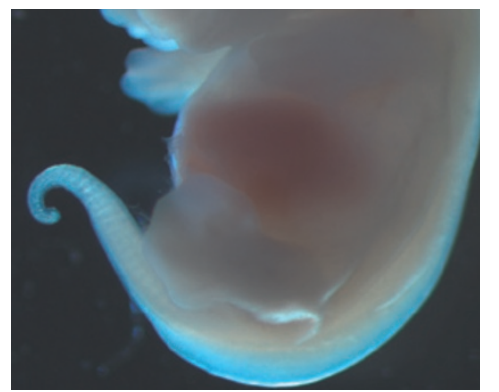

AGRICULTURE

\section{Heat hurts crop production}

Climate change has suppressed food production around the world during the past three decades, according to modelling work. Global maize (corn) production, for example, is estimated to be $3.8 \%$ lower than it would have been if Earth were not warming.

David Lobell at Stanford University in California and his co-authors analysed links between national yields and temperature and precipitation trends from 1980 to 2008 . They estimate that, despite the fertilizing effect of increased carbon dioxide in the atmosphere, wheat production has dropped by $2.5 \%$. However, thanks to the $\mathrm{CO}_{2}$ boost, yields of rice are up by $2.9 \%$ and soya beans by $1.3 \%$. The United States, which produces about $40 \%$ of the world's soya and maize, has so far been unaffected because its crop-growing regions haven't warmed much in summer.

Overall, the changes wrought by the warming climate during the study period bumped up food commodity prices worldwide by about $6.4 \%$, the authors suggest.

Science doi:10.1126/ science.1204531 (2011)

For a longer story on this research, see go.nature.com/ rk1fni

\section{$\rightarrow$ NATURE,COM}

For the latest research published by Naturevisit:

www.nature.com/latestresearch 